Working Paper 9410

\title{
TAX STRUCTURE, WELFARE, AND THE STABILITY OF EQUILIBRIUM IN A MODEL OF DYNAMIC OPTIMAL FISCAL POLICY
}

by Jang-Ting Guo and Kevin J. Lansing

Jang-Ting Guo is a professor of economics at the University of California, Riverside, and Kevin J. Lansing is an economist at the Federal Reserve Bank of Cleveland. For helpful comments, the authors thank David Altig, Costas Azariadis, Roger Farmer, Gary Hansen, Finn Kydland, and seminar participants at the 1994 SEDC conference and the UCLA Tuesday evening Macro Workshop.

Working papers of the Federal Reserve Bank of Cleveland are preliminary materials circulated to stimulate discussion and critical comment. The views stated herein are those of the authors and not necessarily those of the Federal Reserve Bank of Cleveland or of the Board of Governors of the Federal Reserve System. 


\begin{abstract}
This paper shows that the assumed structure of taxation can have dramatic effects on economic welfare and the stability of the steady state in a dynamic general-equilibrium model of optimal fiscal policy. Specifically, tax structure refers to the use of separate versus uniform tax rates on labor and capital income, the level of taxation of firm dividends (single versus double taxation), and the tax treatment of depreciation. Under each tax structure, the government selects a balanced-budget fiscal policy (consisting of tax rates and the level of public expenditures) which maximizes the welfare of the representative household. We find that household welfare is highest under a tax structure that includes separate tax rates on labor and capital income, double taxation of dividends, and tax deductible depreciation. Moreover, single taxation of dividends yields an unstable steady state under a structure with separate tax rates on labor and capital income and tax deductible depreciation. This instability, which is robust to changes in parameter values, can be removed by implementing various changes to the tax structure, such as (1) imposing double taxation of dividends, (2) taxing labor and capital income at the same rate, or (3) eliminating the depreciation allowance. Of these three options, imposing double taxation of dividends yields the highest welfare.
\end{abstract}




\section{Introduction}

This paper shows that the assumed structure of taxation can have dramatic effects on economic welfare and the stability of the steady state in a dynamic general-equilibrium model of optimal fiscal policy. Specifically, tax structure refers to the use of separate versus uniform tax rates on labor and capital income, the level of taxation of firm dividends (single versus double taxation), and the tax treatment of depreciation. The framework for the analysis is a deterministic, infinite-horizon representative household model in which the government solves a dynamic version of the Ramsey (1927) optimal tax problem. Public capital serves as a direct input to the firm's neoclassical production function, which exhibits constant returns to scale in all inputs, public and private. As a result, the firm retains positive profits equal to public capital's share of output.

Within the constraints defined by each tax structure, we endogenize the choice of fiscal policy by solving for the optimal tax rates and the optimal levels of public consumption and public investment that maximize household utility. We consider three distinct aspects of the tax structure. First, we examine the effects of taxing all types of income at the same rate (a so-called uniform income tax), versus a structure that allows for separate tax rates on labor and capital income. ${ }^{1}$ Second, we postulate that profits are initially taxed at the firm level, and study the effects of allowing the government to tax profits a second time when they are distributed to households in the form of dividends. Third, we consider the effects of eliminating the tax deductibility of depreciation. The various tax structures are compared in terms of economic welfare (as measured by steady-state utility), output (as measured by steady-state GNP), and the local stability of the steady state.

Our primary finding is that household welfare is highest under a tax structure that includes separate tax rates on labor and capital income, double taxation of dividends, and tax deductible depreciation. From the perspective of choosing an optimal fiscal policy, a uniform tax structure imposes an additional constraint on the government's decision problem, namely, that the tax rate on labor income must be equal to the tax rate on capital income. Because a policy of equal tax rates is available to the government under a more general tax structure, but is not chosen, we know that the additional constraint is binding and thus results in a lower level of household utility than in the unconstrained case. From the

\footnotetext{
${ }^{1}$ See Guo and Lansing (1994) for a more detailed analysis of this aspect of tax structure in a related model.
} 
standpoint of economic welfare, double taxation of dividends is superior to single taxation because it allows the government to recapture a larger percentage of public capital's share of output. If a separate profits tax were available, the government would choose to tax profits at a rate of 100 percent. Effectively, the tax on profits acts like a user fee for productive services of public capital. Double taxation improves welfare because it comes closer to the ideal confiscatory rate than does single taxation. Furthermore, the additional tax revenue is used to finance public consumption and public investment (both of which provide benefits to households), and permits the use of a lower tax rate on labor income. Finally, the depreciation allowance improves household welfare because it operates as an implicit subsidy to capital accumulation, and partially offsets the distortion associated with taxing income from capital. As we have previously shown in a related paper (see Guo and Lansing [1994]), the welfare cost of eliminating the depreciation allowance is quite high, over 2 percent of GNP, a fact which highlights the importance of this tax break in encouraging capital formation.

An additional, rather interesting finding is that single taxation of dividends yields an unstable long-run equilibrium under a structure which includes separate tax rates on labor and capital income and tax deductible depreciation. In this case, we find that the Jacobian matrix of the linearized dynamical system (in the neighborhood of the steady state) displays too many explosive eigenvalues. This indicates that the long-run equilibrium cannot be characterized by a stable set of stationary policy rules. This instability, which is robust to changes in parameter values, can be removed by implementing various changes to the tax structure, such as (1) imposing double taxation of dividends, (2) taxing labor and capital income at the same rate, or (3) eliminating the depreciation allowance. Of these three options, imposing double taxation of dividends yields the highest level of household welfare.

Our results highlight the importance of taking into account both the structure of the tax system and the level of tax rates in considering policies designed to improve welfare or stabilize the economy. Moreover, our results suggest a possible justification for some observed features of the U.S. tax system, such as the coexistence of the corporate income tax with the practice of subjecting dividends to the personal income tax. Some previous related research includes Arrow and Kurz (1970), who employ an optimal growth model with public capital to discuss the theoretical possibility of multiple steady states exhibiting different stability properties. Cooley and Hansen (1992) evaluate the welfare effects of various 
combinations of exogenous taxes in a neoclassical monetary economy. Finally, Pecorino (1993) and Stokey and Rebelo (1993) study the effects of tax structure on economic growth in endogenous growth models with human capital.

The remainder of this paper is organized in the following manner: Sections 2 and 3 describe the model and the methods we use to compute the steady state and determine the stability of the longrun stationary equilibrium. The choice of parameter values is discussed in section 4 . Section 5 presents quantitative welfare comparisons based on steady-state analysis. Section 6 concludes.

\section{The Model}

The model economy consists of many identical, infinitely lived households, identical private firms, and the government. The government finances expenditures on public consumption goods and public investment goods by levying distortionary taxes on households and firms. All goods (public and private) are produced using a privately owned, Cobb-Douglas technology that exhibits constant returns to scale in the three productive inputs: labor, private capital, and public capital. The form of the technology implies that private firms earn an economic profit equal to the difference between the value of output and payments to private factor inputs. The purpose of introducing profits is to obtain a positive optimal tax rate on capital, consistent with U.S. observations. ${ }^{2}$ As owners of the firms, households receive net profits in the form of dividends, but consider them to be outside their control, similar to wages and interest rates. We assume that the government can distinguish between labor and capital income, but cannot distinguish between the different categories of capital income, such as profits, dividends, and capital rental income. Therefore, our model includes only two types of distortionary taxes: a labor tax and a capital tax.

\subsection{The Household's Problem}

Households maximize a discounted stream of within-period utility functions over consumption and leisure, subject to a sequence of budget constraints. The decision problem can be summarized as

\footnotetext{
${ }^{2}$ Jones, Manuelli, and Rossi (1993) show that the existence of profits and a restriction on the menu of available tax instruments (the absence of a separate profits tax) is one method of obtaining a positive optimal tax rate on capital in the steady state. Without profits, the optimal steady-state tax on capital is zero (see Judd [1985] and Chamley [1986]).
} 
clevelandfed.org/research/workpaper/index.cfm

$$
\max _{c_{t}, h_{t}, k_{t+1}} \sum_{t=0}^{\infty} \beta^{t}\left\{\ln c_{t}-A h_{t}+B \ln g_{t}\right\} \quad 0<\beta<1, \quad A, B \geq 0
$$

subject to

$$
\begin{gathered}
c_{t}+x_{t} \leq\left(1-\tau_{h t}\right) w_{t} h_{t}+\left(1-\tau_{k t}\right)\left(r_{t} k_{t}+\pi_{t}\right)+\phi \tau_{k t} \delta k_{t}, \quad \phi=\{1,0\} \\
k_{t+1}=(1-\delta) k_{t}+x_{t} \quad 0<\delta<1, \quad k_{0} \text { given. }
\end{gathered}
$$

In the above equations, $\beta$ is the constant household discount factor and $c_{t}$ represents private consumption goods. Households are endowed with one unit of time each period and work $h_{t}$ hours during period $t$. Household preferences also include a separable term representing the utility provided by public consumption goods $g_{t}$. Examples of public consumption goods that might affect household utility are national defense, police protection, and government provision of food and housing during natural disasters. Public goods are assumed to be noncongestable and free of specific user charges.

Households maximize the utility function in (1) over $c_{t}$ and $h_{t}$, but view $g_{t}$ as outside their control. The form of the within-period utility function has been chosen for tractability. The fact that utility is linear in hours worked reflects the "indivisible labor" formulation, as described by Rogerson (1988) and Hansen (1985). The separability in $c_{t}$ and $g_{t}$ implies that public consumption does not affect the marginal utility of private consumption, a specification supported by parameter estimates in McGrattan, Rogerson, and Wright (1993). We introduce no uncertainty into this model because our analysis focuses on steady-state welfare comparisons and the stability properties of a linearized dynamical system that exhibits the property of certainty equivalence.

Equation (2) represents the period budget constraint of the household. The terms $x_{t}$ and $k_{t}$ represent gross private investment and private capital, respectively. Households derive income by supplying labor and capital services to firms at rental rates $w_{t}$ and $r_{t}$ and pay taxes on labor and capital income at rates $\tau_{h t}$ and $\tau_{k t}$, respectively. An additional source of income is the firms' net profits $\hat{\pi}_{t}$, which are distributed to households as dividends and are taxed at the same rate as capital rental income $r_{t} k_{t}$. The term $\phi \tau_{k t} \delta k_{t}$ represents the depreciation allowance, where the parameter $\phi$ can be set to either 1 or 0 , depending on whether this tax break is included as part of the tax structure. Equation (3) is the 
law of motion for private capital, given a constant rate of depreciation $\delta$. Households view tax rates, wages, interest rates, and dividends as determined outside their control.

\subsection{Household Optimality}

The Lagrangian for the household's problem is defined as

$$
\begin{gathered}
\mathscr{Q}=\sum_{t=0}^{\infty} \beta^{t}\left\{\ln c_{t}-A h_{t}+B \ln g_{t}+\right. \\
\left.\lambda_{t}\left[\left(1-\tau_{h t}\right) w_{t} h_{t}+\left(1-\tau_{k t}\right)\left(r_{t} k_{t}+\hat{\pi}_{t}\right)+\phi \tau_{k t} \delta k_{t}-k_{t+1}+(1-\delta) k_{t}-c_{t}\right]\right\} .
\end{gathered}
$$

The household first-order conditions with respect to the indicated variables and the associated transversality conditions (TVC) are

$$
\begin{aligned}
c_{t}: & \lambda_{t}=\frac{1}{c_{t}} \\
h_{t}: & \lambda_{t}\left(1-\tau_{h t}\right) w_{t}=A \\
k_{t+1}: & \lambda_{t}=\beta \lambda_{t+1}\left[\left(1-\tau_{k t+1}\right) r_{t+1}-\left(1-\phi \tau_{k t+1}\right) \delta+1\right] \\
\text { TVC: } & \lim _{t \rightarrow \infty} \beta^{t} \lambda_{t} k_{t+1}=0 .
\end{aligned}
$$

The government's problem is solved by finding the set of welfare-maximizing allocations $c_{t}, h_{t}$ and $k_{t+1}$, such that the household's first-order conditions (5) and budget constraint (2) are satisfied. Given these optimal allocations, the government uses the household equilibrium conditions to recover the appropriate tax rates $\tau_{h t}$ and $\tau_{k t}$ that will support these allocations in a decentralized economy. ${ }^{3}$

\footnotetext{
${ }^{3}$ See Chari, Christiano, and Kehoe (1993) for a more complete discussion of this equilibrium concept.
} 


\subsection{The Firm's Problem}

Output $\left(y_{t}\right)$ is produced by identical private firms which seek to maximize after-tax profit, subject to a technology that exhibits constant returns to scale in the three productive inputs, $h_{t}, k_{t}$ and $k_{G t}$, where $k_{G t}$ is the stock of public capital. The firm's profits are taxed at the rate $\tau_{k t}$. The firm's decision problem can be summarized as follows:

$$
\max _{k_{1}, h_{r}}\left(1-\tau_{k t}\right)^{\psi-1}\left(y_{t}-r_{t} k_{t}-w_{t} h_{t}\right), \quad \Psi=\{2,1\}
$$

subject to

$$
y_{t}=k_{t}{ }^{\theta_{1}} h_{t}^{\theta_{2}} k_{G t}^{\theta_{3}} \quad 0<\theta_{i}<1, \quad \theta_{1}+\theta_{2}+\theta_{3}=1
$$

In (6), the parameter $\psi$ controls the level of taxation of firm dividends. When $\psi=2$, dividends are taxed twice; once at the firm level and again at the household level. When $\psi=1$, dividends are taxed only once, at the household level. This formulation of double taxation reflects the idea that only a portion of the total income from capital is taxed twice. Capital rental income $\left(r_{t} k_{t}\right)$ is taxed only once, at the rate $\tau_{k t}$, regardless of the value of $\psi$. The firm's first-order conditions are ${ }^{4}$

$$
r_{t}=\theta_{1} \frac{y_{t}}{k_{t}} \quad w_{t}=\theta_{2} \frac{y_{t}}{h_{t}}
$$

The firm's after-tax profits, distributed to households in the form of dividends, are

$$
\hat{\pi}_{t}=\left(1-\tau_{k t}\right)^{\psi-1}\left(1-\theta_{1}-\theta_{2}\right) y_{t}
$$

\subsection{The Government's Problem}

The government chooses an optimal program of taxes and public expenditures in order to maximize the discounted utility of the household. This is a dynamic version of the Ramsey (1927) optimal tax problem, involving a Stackelberg game between the government and households. To avoid

\footnotetext{
4There is no need to distinguish between variables under the household's control and variables representing "per capita" quantities here, as must be done when solving directly for a decentralized equilibrium. As pointed out by Lucas and Stokey (1983), the solution to the government's (centralized) decision problem yields a set of policies which dictate household equilibrium allocations. These allocations determine the equilibrium prices $r_{t}$ and $w_{t}$. Thus, prices are not outside the control of the government, which differs in this respect from an individual household.
} 
time-consistency problems, we assume that the government can commit to a set of state-contingent, stationary policy rules announced at time zero. Also, to make the problem interesting, we rule out any time-zero levies on private-sector assets that might be used to finance all future expenditures. In addition, we assume that the government adheres to a period-by-period balanced-budget constraint. ${ }^{5}$ With these assumptions, the government's problem is

$$
\max _{k_{g_{1,+1}}, g_{t}, \tau_{m,}, \tau_{t},} \sum_{t=0}^{\infty} \beta^{t}\left\{U\left(c_{t}, h_{t}, g_{t}\right)\right\}
$$

subject to

(i) household first-order conditions and budget constraint,

(ii) firm profit maximization conditions,

$$
g_{t}+x_{G t}=\tau_{h t} w_{t} h_{t}+\tau_{k t}\left(r_{t}-\phi \delta\right) k_{t}+\left[1-\left(1-\tau_{k t}\right)^{\psi}\right]\left(1-\theta_{1}-\theta_{2}\right) y_{t}
$$

(iv) $k_{G t+1}=\left(1-\delta_{G}\right) k_{G t}+x_{G t}, \quad k_{G 0}$ given,

(v) $\lim _{t \rightarrow \infty} \beta^{t} \Lambda_{G t} k_{G t+1}=0$,

(vi) $\tau_{h t}=\tau_{k t}=\tau_{t}$ (for the uniform tax structure).

Constraints (i) and (ii) summarize rational maximizing behavior on the part of private agents and constitute "implementability" constraints imposed on the government's choice of policy. Constraint (iii) is the government budget constraint, where the last term on the right-hand side reflects the structure of dividend taxation. Constraint (iv) is the law of motion for public capital, given a constant rate of depreciation $\delta_{G}$ and gross public investment $x_{G t}$. Constraint $(v i)$ is a transversality condition on the accumulation of public capital, where $\Lambda_{G t}$ is the marginal utility of public consumption $g_{t}$. Finally, (vi) specifies the constraint associated with the uniform income tax. The vector $\mathcal{P}_{t}=\left\{x_{G t}, g_{t}, \tau_{h t}, \tau_{k t}\right\}$ summarizes government policy at time $t$. The summation of the household budget constraint (2) and the government budget constraint ( $i i i)$ yields the following resource constraint for the economy:

\footnotetext{
${ }^{5}$ Adding government debt to the model introduces complications that we wish to avoid here. Specifically, the perfect foresight equilibrium for a model with debt and capital imposes an arbitrage condition on the returns from government bonds and private capital. The steady-state level of debt is thus indeterminate (see Chamley [1985]). Furthermore, government debt introduces another state variable which increases the dimensionality of the dynamical system we intend to analyze.
} 
clevelandfed.org/research/workpaper/index.cfm

$$
y_{t}=c_{t}+g_{t}+x_{t}+x_{G t}
$$

Because the resource constraint and the government budget constraint are not independent equations, equation (11) will be used in place of (iii) in solving the government's problem.

\section{Solution of the Model}

To facilitate computation of the long-run stationary equilibrium, the government's problem specified in (10) is rewritten as the following infinite-horizon sequence problem:

$$
\max _{\substack{k_{t+1}, k_{G+1+1}, \lambda_{1,} h_{1}}} \sum_{t=1}^{\infty} \beta^{t}\left\{\ln \left(1 / \lambda_{t}\right)-A h_{t}+B \ln \left[y_{t}-\frac{1}{\lambda_{t}}-k_{t+1}+(1-\delta) k_{t}-k_{G t+1}+\left(1-\delta_{G}\right) k_{G t}\right]\right\}
$$

subject to

$$
\begin{gathered}
\frac{A h_{t}}{\lambda_{t}}+\frac{\lambda_{t-1}}{\beta \lambda_{t}} k_{t}+\left(1-\theta_{1}-\theta_{2}\right) y_{t}\left[\frac{\frac{\lambda_{t-1}}{\beta \lambda_{t}}-1+\delta(1-\phi)}{r_{t}-\phi \delta}\right]^{\psi}-\frac{1}{\lambda_{t}}-k_{t+1}=0 \\
\frac{A}{w_{t} \lambda_{t}}-\left[\frac{\frac{\lambda_{t-1}}{\beta \lambda_{t}}-1+\delta(1-\phi)}{r_{t}-\phi \delta}\right]=0 \quad \text { (for the uniform } \\
y_{t}=k_{t}^{\theta_{1}} h_{t}^{\theta_{2}} k_{G t}^{\theta_{3}} \\
r_{t}=\theta_{1} \frac{y_{t}}{k_{t}}, \quad w_{t}=\theta_{2} \frac{y_{t}}{h_{t}}
\end{gathered}
$$

To obtain the formulation in (12), we first substitute the household first-order conditions shown in (5) into the household budget constraint (2), the resource constraint (11), and the household utility function to eliminate $\tau_{t t}, \tau_{k t}$, and $c_{t}$. The resource constraint (11) is then used to substitute out $g_{t}$. Following the solution method of Kydland and Prescott (1980), we define the household lagged-shadow price $\lambda_{t-1}$ to be a "pseudo-state variable" for our analysis. Including $\lambda_{t-1}$ in the state vector provides a link to the past by which the policymaker at time $t$ considers the fact that household decisions in earlier 
periods depend on current policy. This is the mechanism by which the commitment assumption is incorporated into the government's decision problem. In (12), the vector of state variables for the government's problem in period $t$ is $s_{t}=\left\{k_{t}, k_{G t}, \lambda_{t-1}\right\}$ and the government's decision variables are $k_{t+1}$, $k_{G t+1}, \lambda_{t}$, and $h_{t}$. The first constraint in (12) is the household budget equation after substituting in the household first-order conditions. The next constraint imposes the condition of equal tax rates on labor and capital income for the uniform tax structure. The remaining constraints define the production technology and the factor prices $r_{t}$ and $w_{t}$.

The sequence problem in (12) applies for all $t>0$. The problem at $t=0$ must be considered separately, as shown by Kydland and Prescott (1980), Lucas and Stokey (1983), and Chamley (1986). At $t=0$, the stock of private capital is fixed. Optimal fiscal policy thus implies a high initial tax on capital to take full advantage of this nondistortionary source of revenue. We assume that this form of lump-sum taxation is insufficient to finance the entire stream of future expenditures. The analysis here will focus on long-run equilibrium, i.e., when $t$ approaches infinity. Since (12) can be written in the form of a recursive dynamic programming problem (see Kydland and Prescott [1980] and Guo and Lansing [1994]), we confine our attention to stationary equilibria. We do not solve the $t=0$ problem or compute the transition path to the steady state.

Given (12), we obtain first-order conditions with respect to $k_{t+1}, k_{G t+1}, \lambda_{t}, h_{t}, \Lambda_{1 t}$, and, for the uniform tax structure, $\Lambda_{2 t}$, where $\Lambda_{1 t}$ and $\Lambda_{2 t}$ are the Lagrange multipliers associated with the first two constraints (the remaining constraints having been eliminated by substitution). To compute the steady state, all time subscripts are dropped from the first-order conditions to form a system of nonlinear equations in the indicated variables. The system is then solved using a nonlinear equation solver. ${ }^{6}$

Under the more general tax structure $\left(\tau_{h t} \neq \tau_{k t}\right)$, the first-order conditions from (12) can be reduced to a system of three second-order, nonlinear difference equations in $k_{t}, k_{G t}$, and $\lambda_{t-1}$. In this case, the first-order condition for $h_{t}$ is used to eliminate $\Lambda_{1 t}$ from the dynamical system, and the (linearized) first-order condition for $\Lambda_{1 t}$ is used to eliminate $h_{t}$. Similar operations are performed for the uniform tax structure $\left(\tau_{h t}=\tau_{k t}\right)$, except that the dynamics for the state variable $\lambda_{t-1}$ are now only first order, and $\Lambda_{1 t}$

\footnotetext{
${ }^{6}$ The NLSYS routine in GAUSS version 3.1.4 was used.
} 
is retained as a variable in the dynamical system. ${ }^{7}$ The steady state is then used to construct a log-linear approximation of the dynamical system under each tax structure. By implementing a transformation of variables $z_{t} \equiv k_{t+1}, u_{t} \equiv k_{G t+1}$, and $v_{t} \equiv \lambda_{t}$, the system can be rewritten as a set of six first-order linear difference equations. The difference equations take the following form, where hat $\left(^{\wedge}\right)$ variables denote deviations from steady-state values in logarithms, and $\mathrm{J}$ is the $6 \times 6 \mathrm{Jacobian}$ matrix for the linearized dynamical system:

$$
\left[\begin{array}{c}
\hat{z}_{t+1} \\
\hat{k}_{t+1} \\
a_{t+1} \\
\hat{k}_{G t+1} \\
\hat{v}_{t+1} \\
\hat{\lambda}_{t}
\end{array}\right]=\mathbf{J}_{6 \times 6}\left[\begin{array}{c}
\hat{z}_{t} \\
\hat{k}_{t} \\
a_{t} \\
\hat{k}_{G t} \\
\hat{v}_{t} \\
\hat{\lambda}_{t-1}
\end{array}\right]
$$

for the more general tax structure, and

$$
\left[\begin{array}{c}
\hat{z}_{t+1} \\
\hat{k}_{t+1} \\
a_{t+1} \\
\hat{k}_{G t+1} \\
\hat{\Lambda}_{1 t+1} \\
\hat{\lambda}_{t}
\end{array}\right]=\mathrm{J}_{6 \times 6}\left[\begin{array}{c}
\hat{z}_{t} \\
\hat{k}_{t} \\
a_{t} \\
\hat{k}_{G t} \\
\hat{\Lambda}_{1 t} \\
\hat{\lambda}_{t-1}
\end{array}\right]
$$

for the uniform tax structure.

Because the government's problem for $t>0$ is recursive, the solutions to the linear systems shown in (13) and (14) consist of a set of stationary policy rules for $k_{t+1}, k_{G t+1}$, and $\lambda_{t}$ which can be expressed as log-linear functions of the state variables $k_{t}, k_{G t}$, and $\lambda_{t-1}$. The stability of the stationary equilibrium is determined by comparing the number of eigenvalues of $\mathbf{J}$ located inside the unit circle to the number of initial conditions (see Farmer [1993]). For this problem, the three predetermined state variables constitute the three initial conditions. When $\mathbf{J}$ has exactly three eigenvalues inside the unit

\footnotetext{
${ }^{7}$ In this case, the first-order condition for $h_{t}$ is used to eliminate $\Lambda_{2 t}$, the (linearized) first-order condition for $\Lambda_{1 t}$ is used to eliminate $h_{t}$, and the first-order condition for $\Lambda_{2 t}$ is used to eliminate $\lambda_{t+1}$. Thus, $\Lambda_{1 t}$ remains in the dynamical system.
} 
circle, the linearized dynamical system possesses a unique set of stable, stationary policy rules in terms of $k_{t}, k_{G t}$, and $\lambda_{t-1}{ }^{8}$ When $\mathrm{J}$ has less than three eigenvalues inside the unit circle, the system explodes. In this case, the long-run equilibrium cannot be characterized by a stable set of stationary policy rules, and we label the system as "unstable."

\section{Calibration of the Model}

To obtain quantitative results from the model, as many parameters as possible are assigned values in advance on the basis of empirically observed features of postwar U.S. data. Table 1 summarizes the choice of parameter values and is followed by a brief explanation of how they were selected. The time period in the model is taken to be one year. This is consistent with the frequency of most government fiscal decisions. Experiments with a quarterly time period $(\beta=0.99, \delta=0.02$, and $\left.\delta_{G}=0.01\right)$ produced qualitatively similar results.

Table 1: Parameter Set

\begin{tabular}{cccc}
\hline \hline Agent & \multicolumn{2}{c}{ Parameters and Values } \\
\hline Households & $\beta=0.962$ & $A=2.60$ & $B=0.28$ \\
\hline \multirow{2}{*}{ Firms } & $\theta_{1}=0.30$ & \\
& $\theta_{2}=0.60$ & & \\
$\theta_{3}=0.10$ & & \\
\hline \multirow{2}{*}{ Government } & $\phi=\{1,0\}$ & $\psi=\{2,1\}$ & $\delta_{G}=0.04$ \\
\hline
\end{tabular}

The discount factor $\beta$ implies an annual rate of time preference of 4 percent. The parameter $A$ in the household utility function is chosen such that the fraction of time spent working is close to 0.3 at the steady-state. The value of $B$ is chosen to yield a steady-state value of $g / G N P$ near 0.17 , the average ratio for the U.S. economy from 1947 to $1992 .{ }^{9}$ The selected values of $\theta_{1}$ and $\theta_{2}$ are in the range of the estimated shares of GNP received by private capital and labor in the U.S. economy (see Christiano [1988]). The output elasticity of public capital, $\theta_{3}$, is chosen to yield a steady-state ratio of

\footnotetext{
${ }^{8}$ At $t=0$, the government's problem cannot be represented by (12), so our approach only allows us to characterize the stability of the long-run stationary equilibrium.

${ }^{9}$ In computing this average, public consumption was estimated by subtracting public investment from an annualized series for government purchases of goods and services (GGEQ from Citibase). This was done to reduce double counting, since the series does not distinguish between government consumption and investment goods.
} 
public investment to GNP ( $\left.x_{G} / G N P\right)$ near 0.05 , based on the U.S. average from 1947 to 1992 . The private capital depreciation rate $\delta$ is consistent with values commonly used in the real business-cycle literature. The public capital depreciation rate, $\delta_{G}$, was estimated by regressing the linear law of motion on annual data for $k_{G t}$ and $x_{G t}$ (see Lansing [1994]).

\section{Steady-State Welfare and Stability}

Based on our choice of parameter values, tables $2 a$ and $2 b$ show the steady-state values of key model variables for each of the various tax structures. In terms of maximizing steady-state utility and output, the "optimum" tax structure can be found in the first column of table 2a. This tax structure includes double taxation of dividends, tax deductible depreciation, and separate tax rates on labor and capital income. A few general observations about the effects of changes to the tax structure can be made. First, holding other aspects of the tax structure constant, the imposition of double taxation of dividends

always causes steady-state utility and output to increase. Second, any tax structure that includes a depreciation allowance yields higher levels of steady-state utility and output than any structure without this tax break. Third, a uniform income tax does almost as well as a structure with separate tax rates on labor and capital income. This last observation is consistent with the results of Guo and Lansing (1994), who employ a model in which profits are introduced by way of monopolistic competition rather than by way of productive public capital. 
Table 2a: Steady-State Comparison of Tax Structures

\begin{tabular}{|c|c|c|c|c|}
\hline \multirow[b]{3}{*}{ Variable } & \multicolumn{4}{|c|}{ Double Taxation of Dividends $(\psi=2)$} \\
\hline & \multicolumn{2}{|c|}{ With Depreciation Allowance $(\phi=1)$} & \multicolumn{2}{|c|}{ No Depreciation Allowance $(\phi=0)$} \\
\hline & $\tau_{h} \neq \tau_{k}$ & $\tau_{h}=\tau_{k}=\tau$ & $\tau_{h} \neq \tau_{k}$ & $\tau_{h}=\tau_{k}=\tau$ \\
\hline Utility & -2.767 & -2.770 & -2.801 & -2.806 \\
\hline GNP $=y$ & 0.464 & 0.457 & 0.436 & 0.437 \\
\hline$c$ & 0.281 & 0.272 & 0.266 & 0.271 \\
\hline$h$ & 0.304 & 0.291 & 0.286 & 0.296 \\
\hline$g$ & 0.080 & 0.078 & 0.073 & 0.073 \\
\hline$k / y$ & 2.136 & 2.260 & 2.129 & 2.001 \\
\hline$k_{G} / y$ & 1.316 & 1.313 & 1.292 & 1.290 \\
\hline$g / y$ & 0.173 & 0.172 & 0.168 & 0.168 \\
\hline Tax Rates & $\begin{array}{l}\tau_{h}=0.205 \\
\tau_{k}=0.347\end{array}$ & $\tau=0.251$ & $\begin{array}{l}\tau_{h}=0.243 \\
\tau_{k}=0.152\end{array}$ & $\tau=0.203$ \\
\hline
\end{tabular}

Table 2b: Steady-State Comparison of Tax Structures

\begin{tabular}{|c|c|c|c|c|}
\hline \multirow[b]{3}{*}{ Variable } & \multicolumn{4}{|c|}{ Single Taxation of Dividends $(\psi=1)$} \\
\hline & \multicolumn{2}{|c|}{ With Depreciation Allowance $(\phi=1)$} & \multicolumn{2}{|c|}{ No Depreciation Allowance $(\phi=0)$} \\
\hline & $\tau_{h} \neq \tau_{k}$ & $\tau_{h}=\tau_{k}=\tau$ & $\tau_{h} \neq \tau_{k}$ & $\tau_{h}=\tau_{k}=\tau$ \\
\hline Utility & -2.792 & -2.793 & -2.816 & -2.829 \\
\hline $\mathrm{GNP}=y$ & 0.442 & 0.439 & 0.423 & 0.421 \\
\hline$c$ & 0.268 & 0.264 & 0.258 & 0.265 \\
\hline$h$ & 0.290 & 0.281 & 0.274 & 0.289 \\
\hline$g$ & 0.075 & 0.074 & 0.069 & 0.069 \\
\hline$k / y$ & 2.140 & 2.240 & 2.202 & 1.973 \\
\hline$k_{G} / y$ & 1.296 & 1.287 & 1.258 & 1.258 \\
\hline$g / y$ & 0.170 & 0.168 & 0.164 & 0.164 \\
\hline Tax Rates & $\begin{array}{l}\tau_{h}=0.238 \\
\tau_{k}=0.345\end{array}$ & $\tau=0.268$ & $\begin{array}{l}\tau_{h}=0.275 \\
\tau_{k}=0.123\end{array}$ & $\tau=0.214$ \\
\hline
\end{tabular}


Table 3 summarizes the welfare and output losses for each of the various tax structures, where the optimum tax structure noted above is used as the baseline for comparison. These figures show that tax structure can have dramatic effects on economic welfare and output, even when the government does its best to maximize the well-being of the household. Starting from the optimum tax structure, a change from double taxation of dividends to single taxation reduces household welfare by over 1.5 percent of GNP, which translates to an annual loss of $\$ 390$ per person in $1993 .{ }^{10}$ Double taxation of dividends is superior to single taxation because it allows the government to recapture a larger percentage of public capital's share of output. If a separate profits tax were available, the government would choose to tax profits at a rate of 100 percent (see Jones, Manuelli, and Rossi [1993]). Effectively, the tax on profits acts like a user fee for the productive services of public capital. Double taxation is welfare improving because it comes closer to the ideal confiscatory rate than does single taxation. Furthermore, the additional tax revenue is used to finance public consumption and public investment, and permits the use of a lower tax rate on labor income.

Table 3 also shows that, starting from the optimum tax structure, eliminating the depreciation allowance will reduce household welfare by over 2 percent of GNP. (This change corresponds to a movement across the first row of table $3 a$ to end up in the third column of the table.) Eliminating the depreciation allowance reduces household welfare because it operates as an implicit subsidy to capital accumulation and partially offsets the distortion associated with taxing income from capital. This occurs even though marginal tax rates on capital income are lower in a structure with no depreciation allowance. Because the government wishes to tax profits as much as possible, a high tax rate on capital combined with a full depreciation allowance is superior to a low tax rate on capital combined with no depreciation allowance. ${ }^{11}$ It is interesting to compare our finding that the depreciation allowance has a large welfare effect to that of Pecorino (1993), who finds that the tax deductibility of depreciation has no effect on the maximum steady-state growth rate in an endogenous growth model.

\footnotetext{
${ }^{10}$ This number is based on a nominal GNP of $\$ 6,510$ billion and total U.S. population of 258.2 million in 1993 .

${ }^{11}$ When profits are zero $\left(1-\theta_{1}-\theta_{2}=0\right)$ and the government can tax labor and capital income separately, eliminating the depreciation allowance has no effect whatsoever on the steady-state allocations. This can be seen from the government's problem in (12) for the generalized tax structure $\left(\tau_{h} \neq \tau_{k}\right)$; note that the depreciation allowance parameter $\phi$ only appears in the profit term of the (transformed) household budget constraint.
} 
Finally, table 3 summarizes the stability properties of the long-run stationary equilibrium, as determined by the method described in section 3 . In the first column of table $3 \mathrm{~b}$, we see that the steady state is unstable under a structure with single taxation of dividends, tax deductible depreciation, and separate tax rates on labor and capital income. In this case, the Jacobian matrix of the linearized dynamical system displays too many explosive eigenvalues (there are four eigenvalues located outside the unit circle and only two inside). This indicates that the solution to the (approximate version of) the government's problem (12) cannot be characterized by a stable set of stationary policy rules. Our experiments indicate that this instability is robust to changes in the following parameters: $\beta, A, B, \theta_{1}$, $\theta_{2}, \theta_{3}, \delta$, and $\delta_{G}$. However, table 4 shows that the instability can be removed by implementing various changes to the tax structure, such as (1) imposing double taxation of dividends, (2) imposing a uniform income tax, or (3) eliminating the depreciation allowance. Of these three options, only one, imposing double taxation of dividends, causes household welfare to increase. Schematically, this option corresponds to a movement from the first column of table $3 \mathrm{~b}$, directly upward, to the first column of table $3 \mathrm{a}$, yielding the optimum tax structure noted earlier.

The high dimensionality of the dynamical system makes it difficult to pinpoint the intuition for the unstable tax structure. However, it appears that the instability is due in some way to the presence of public capital as an endogenous state variable. With productive public capital, the dynamical system is characterized by a $6 \times 6$ Jacobian matrix. We have experimented with an otherwise similar model without public capital (see Guo and Lansing [1994]), which is described by a $4 \times 4$ Jacobian matrix, and found no unstable tax structures. We have also experimented with the use of noninteger values for the tax structure parameters $\psi$ and $\phi$. Starting from the unstable tax structure, we found that values of $\psi \geq 1.19$ or $\phi \leq 0.11$ remove the instability. Thus, a stable tax structure can be obtained by taxing dividends only slightly higher than single taxation or by allowing only a small fraction of depreciation expenses to be tax deductible. 
Table 3a: Welfare and Output Losses and Long-Run Stability

\begin{tabular}{|c|c|c|c|c|}
\hline & \multicolumn{4}{|c|}{ Double Taxation of Dividends $(\psi=2)$} \\
\hline & \multicolumn{2}{|c|}{ With Depreciation Allowance $(\phi=1)$} & \multicolumn{2}{|c|}{ No Depreciation Allowance $(\phi=0)$} \\
\hline & $\tau_{h} \neq \tau_{k}$ & $\tau_{h}=\tau_{k}=\tau$ & $\tau_{h} \neq \tau_{k}$ & $\tau_{h}=\tau_{k}=\tau$ \\
\hline $\begin{array}{c}\text { Welfare Loss } \\
\Delta U /(\lambda y)^{\mathrm{a}}\end{array}$ & baseline & $0.175 \%$ & $2.048 \%$ & $2.377 \%$ \\
\hline $\begin{array}{c}\text { Output Loss } \\
\Delta y / y\end{array}$ & baseline & $1.590 \%$ & $6.198 \%$ & $5.915 \%$ \\
\hline Long-Run Stability & stable & stable & stable & stable \\
\hline
\end{tabular}

${ }^{\mathrm{a}} \Delta U$ and $\Delta y$ are normalized using the steady-state values of $\lambda$ and $y$ from the baseline tax structure $(\psi=2, \phi=1$, and $\tau_{h} \neq \tau_{k}$ ), where $\lambda$ is the marginal utility of private consumption (to convert $\Delta U$ into consumption units) and $y$ is GNP.

Table 3b: Welfare and Output Losses and Long-Run Stability

\begin{tabular}{|c|c|c|c|c|}
\hline & \multicolumn{4}{|c|}{ Single Taxation of Dividends $(\psi=1)$} \\
\hline & \multicolumn{2}{|c|}{ With Depreciation Allowance $(\phi=1)$} & \multicolumn{2}{|c|}{ No Depreciation Allowance $(\phi=0)$} \\
\hline & $\tau_{h} \neq \tau_{k}$ & $\tau_{h}=\tau_{k}=\tau$ & $\tau_{h} \neq \tau_{k}$ & $\tau_{h}=\tau_{k}=\tau$ \\
\hline $\begin{array}{c}\text { Welfare Loss } \\
\Delta U /(\lambda y)\end{array}$ & $1.547 \%$ & $1.583 \%$ & $2.945 \%$ & $3.716 \%$ \\
\hline $\begin{array}{c}\text { Output Loss } \\
\Delta y / y\end{array}$ & $4.819 \%$ & $5.543 \%$ & $8.937 \%$ & $9.298 \%$ \\
\hline Long-Run Stability & unstable & stable & stable & stable \\
\hline
\end{tabular}

Table 4: Policy Options to Remove Long-Run Instability

\begin{tabular}{|c|c|c|c|}
\hline & \multicolumn{3}{|c|}{ Policy Change to Tax Structure } \\
\hline & $\begin{array}{c}\text { Impose Double Tax of } \\
\text { Dividends }\end{array}$ & $\begin{array}{c}\text { Impose Uniform Tax } \\
\text { Structure }\end{array}$ & $\begin{array}{c}\text { Eliminate Depreciation } \\
\text { Allowance }\end{array}$ \\
\hline $\begin{array}{c}\text { Change in Welfare } \\
\Delta U /(\lambda y)^{\mathrm{a}}\end{array}$ & $+1.555 \%$ & $-0.036 \%$ & $-1.405 \%$ \\
\hline
\end{tabular}

${ }^{\mathrm{a}} \Delta U$ and $\Delta y$ are normalized using the steady-state values of $\lambda$ and $y$ from the unstable tax structure $(\psi=1, \phi=1$, and $\tau_{h} \neq \tau_{k}$ ), where $\lambda$ is the marginal utility of private consumption (to convert $\Delta U$ into consumption units) and $y$ is GNP. 


\section{Concluding Remarks}

We have examined the welfare implications of some basic features of the U.S. tax code, namely, the double taxation of dividends, the tax deductibility of depreciation, and the practice of taxing labor income differently from capital income. We find that all three of these features are desirable from the standpoint of maximizing the welfare of the representative household. Moreover, we find that movements away from this optimum tax structure can not only reduce economic welfare and output, but can also produce unstable dynamics in our model economy. While our model is admittedly a very abstract and simplified representation of the vastly complex U.S. tax code, we believe that models of this type can be useful for examining key questions about the institutional structure of our tax system. In our view, the strength of this model lies in its ability to capture the general-equilibrium effects of endogenous fiscal policy. In our future research, we plan to address other features of the U.S. tax structure, such as the effects of tax progressivity in an economy with heterogeneous agents. 


\section{REFERENCES}

Arrow, Kenneth J. and Mordecai Kurz. (1970). Public Investment, the Rate of Return, and Optimal Fiscal Policy. Baltimore: Johns Hopkins Press.

Chamley, Christophe P. (1985). "Efficient Taxation in a Stylized General-Equilibrium Model of Intertemporal General Equilibrium," International Economic Review, 26, 451-468.

. (1986). "Optimal Taxation of Income in General-Equilibrium with Infinite Lives," Econometrica, 54, 607-622.

Chari, V.V., Lawrence J. Christiano, and Patrick J. Kehoe. (1993). "Optimal Fiscal Policy in a Business Cycle Model," National Bureau of Economic Research, Working Paper No. 4490.

Christiano, Lawrence J. (1988). "Why Does Inventory Investment Fluctuate So Much?" Journal of Monetary Economics, 21, 247-280.

Cooley, Thomas F. and Gary D. Hansen. (1992). "Tax Distortions in a Neoclassical Monetary Economy," Journal of Economic Theory, 58, 290-316.

Farmer, Roger E.A. (1993). The Macroeconomics of Self-Fulfilling Prophecies. Cambridge MA: MIT Press.

Guo, Jang-Ting and Kevin J. Lansing. (1994). "The Welfare Effects of Tax Simplification: A General-Equilibrium Analysis," Federal Reserve Bank of Cleveland, Working Paper 9409.

Hansen, Gary D. (1985). "Indivisible Labor and the Business Cycle," Journal of Monetary Economics, 16, 309-327.

Jones, Larry E., Rodolfo Manuelli, and Peter E. Rossi. (1993). "On the Optimal Taxation of Capital Income," National Bureau of Economic Research, Working Paper No. 4525.

Judd, Kenneth L. (1985). "Redistributive Taxation in a Simple Perfect Foresight Model," Journal of Public Economics, 28, 59-83.

Kydland, Finn E. and Edward C. Prescott. (1980). "Dynamic Optimal Taxation, Rational Expectations, and Optimal Control," Journal of Economic Dynamics and Control, 2, 79-91.

Lansing, Kevin J. (1994). "Optimal Fiscal Policy When Public Capital is Productive: A Business Cycle Perspective," Federal Reserve Bank of Cleveland, Working Paper 9406.

Lucas, Robert E., Jr. and Nancy L. Stokey. (1983). "Optimal Fiscal and Monetary Policy in an Economy without Capital," Journal of Monetary Economics, 12, 55-94.

McGrattan, Ellen R., Richard Rogerson, and Randall Wright. (1993). "Household Production and Taxation in the Stochastic Growth Model," Federal Reserve Bank of Minneapolis, Staff Report No. 166.

Pecorino, Paul. (1993). "Tax Structure and Growth in a Model with Human Capital," Journal of Public Economics, 52, 251-271.

Ramsey, F.P. (1927). "A Contribution to the Theory of Taxation," Economic Journal, 37, 47-61.

Rogerson, Richard. (1988). "Indivisible Labor, Lotteries, and Equilibrium," Journal of Monetary Economics, 21, 3-16.

Stokey, Nancy L. and Sergio Rebelo. (1993). "Growth Effects of Flat-Rate Taxes," National Bureau of Economic Research, Working Paper No. 4426. 